\title{
The Establishment Features and Enlightenment of the Chinese Women Vocational Schools (1928-1936) -Based on the Investigation of ShenBao
}

\author{
Cheng Yan ${ }^{1}$ \\ School of Education, Tianjin University
}

\begin{abstract}
The purpose of this study is to reveal the reasons for the emergence of women's vocational schools in modern China, and to discuss the characteristics of women's vocational schools. The foundation of modern Chinese women vocational schools was based on the distinct era background. This tide was unceasingly along with the woman's liberation movement, the gradually awakening of woman's self-consciousness, the social needs, as well as the supporting by personages of all circles. At the same time, the modern woman's vocational school established its distinctive features. First of all, diversified units contributed their energy towards woman's vocational education. The main body of the establishment was pluralistic and inclusive of the government's running schools, private schools and joint schools; Secondly, the type of vocational education and professional category were diversitied; thirdly, vocational schools focused on the students' learning environment and job prospects. The conclusion of this study : As the most influencing media of Shanghai then, ShenBao exerted important effect in guiding public opinions. The women vocational schools in modern times, by means of the ShenBao, have been especially effective in the advancement of woman's social status and overall social progress. The development history of the modern Chinese women vocational schools provides a variety of sources for the development of relevant fields. This is also an innovation in this study.
\end{abstract}

Keywords-Woman's vocational schools; Declarations; Woman's liberation; Characteristics

\section{INTRODUCTION}

With the entrance of western culture, women vocational schools were introduced to China. The establishment of these schools was also based on the development of Chinese modern industrial revolution, and thus reflected strong native traits. After the first national revolution in 1927, Chinese society was able to develop in a relatively stable state. During $1928-1936$, the development of Chinese education has come to a peak and the progress of vocational schooling was a significant part of it. More specifically speaking, modern women vocational schools contributed a great deal in educating high-skilled working women.

ShenBao is one of the earliest and most influential mainstream newspapers in modern China. It documents social history of modern China and is of great importance for us to

${ }^{1}$ Cheng Yan (1994 - ), male, from Xuchang, Henan, has a master's degree in education from the school of education, Tianjin University. understand that period of time.

Chinese modern women vocational schools mainly originated in eastern coastal areas, especially in Shanghai, Tianjin and Beijing. These places are influenced by western culture earlier than other regions. This article aims at the motivations and features of modern women vocational schools from the media perspective, so as to reveal the historical inspiration.

\section{THE FOUNDER OF MOTIVATION}

\section{A. The impact of modern women liberation concept}

Since mid 19th century, the East and West civilization in the collision of communication, the Chinese society westward trend began to appear, and the Chinese society moved from closed to open, the society began to emerge new changes.

The development of women education is an important manifestation of the modern women liberation movement [1]. Under the profound influence of the Chinese women liberation movement, women have come out of the shackles of "no talent is virtue", and the pursuit of "talent" is becoming more and more popular. And China mordent women education got development. "The revitalization of female school" of morden Chinese originated in the Reform Movement of 1898, Under the Western ideas and the influence of the church, the reformer founded the first Chinese female school by theirselves. The establishment of modern Chinese women vocational schools not only to meet the women to master the application, but also for the national industrial development and provides a new impetus for social progress.

In the context of the rising status of women, the increased awareness of women, the need for society to provide participation and job opportunities for women emancipation. There has been a large number of modern women vocational schools aimed at "improving women ability and status" throughouting the modern China [2]. Especially in the 1928 to 1936 Nanjing National Government advocated women vocational education and women liberation 


\section{B. The direct promotion of social needs}

China's modern industry since the Westernization Movement, has been in a poor stability as "wave type" development. But in 1928 to 1936, in a relatively stable political environment and relatively positive economic policy support, China's modern industrial development into a climax period. In this period, with the development of modern Chinese industrialization and modern service industry, the demand for the application of skilled female labor force in Chinese society, especially in the eastern region, has become increasingly strong Women have entered the society and have been involved in industrial and agricultural labor. In the promotion of social needs and the community on the women vocational education, China's modern women vocational schools began to appear.

Jiangnan region since ancient times riched in silk, and its mass production and even in short supply appeared in modern times. Since modern times, the church school has developed rapidly in the south of the Yangtze River, the proportion of women literacy learning has been gradually improved. Women have grown into new forces for the development of light industry, but the number of female workers still can not meet the needs of society. For example, the southern region of the silk manufacturing industry, the social needs of women workers is very obvious, this period in Jiangsu Province, "to develop (silk industry), the need for silk staff, the need for silk skills even more..." In such circumstances, the Soviet Department of Agriculture headed by Wu Sunpu, establishing the Jiangsu Provincial woman's Sericulture School to supplement the lack of labor.

The development of modern women vocational schools not only from the needs of society, but also from the community support for women vocational education. As Cai Yuanpei said, "women do not learn, there is no self-reliance and all is depended on men" With the rapid development of society, the degree of concern for women education has been an unprecedented improvement than the past [3]. At the same time, in the modern women education, the attention of the special population has always existed, "graduated from the University of Social Sciences Department of Zhou Zhenshao in Daxia University, and graduated from the woman's secondary school in Shanghai of Shi Ruiyu, explain the importance of the young out of school and unemployed women tutorial education.

It can be seen that the establishment of the Shanghai Women Tutoring School aims to provide education for women who are unemployed and to provide the right and place to be educated on the basis of their own capacity. The construction and development of modern women cram schools also have pushed the crash of modern women professional skill and the purpose of improving the life of vulnerable groups.

\section{SCHOOL RUNNING CHARACTERISTICS}

On the school running characteristics of modern Chinese women vocational schools from ShenBao, there are three points of concern. The school investors were a situation of tripartite confrontation, and the type of school and the setting of subjects are abundant. Student's life and employment have been paid more attention in modern China.

\section{A. The school investors were in a situation of tripartite confrontation}

At present, China's vocational schools are mostly opened by the government, and there are also some private vocational schools. Today, China has fewer joint schools. According to the ShenBao records. The investors of women vocational schools in modern China mainly come from three aspects: Private schools, joint schools and government running schools.

First, private schools are common in modern woman's vocational schools. In 1929, Mrs. Feng, Li Dequan, founded the senior women vocational school and appointed Qi Shuyun to recruit students. As a government insider, Li Dequan of the social celebrities has always paid more attention to the development of education. In the north of China, woman's vocational school was founded. On the one hand, it was responsible for social responsibility. On the other hand, it paid more attention to the education of women in modern China. In the south, "Ms. Dai Shuyun of Hefei, for the high students of Beiping Normal University, rich knowledge and enthusiasm, is willing to sacrifice everything for the cause of education. Now the Shanghai law concession Beller road set up a woman's vocational school, known as Peihua", and "Declaration" more praise Dai Shuyun "rich in learning and management."

Second, the joint school is also very common in modern woman's vocational schools, such as the textile enterprise "Sanyou industrial society", because of its enterprise characteristics, for the cultivation of modern Chinese woman's textile professional technicians to create conditions. In the autumn of 1930, "Shanghai Sanyou industrial society to promote woman's vocational education, to Chinese woman's vocational education agency to do the woman's new sewing Institute..." with the degree of junior high school or the same students as the qualified, the Sanyou cooperatives call Yang Nanyujun as the director of the cloud." It can be seen that the establishment of woman's vocational schools in modern China has the joint establishment mode of industry and Commerce and educational organizations.

Thirdly, government running is the third source of modern woman's vocational schools. "Nanjing woman's professional half day school, formerly known as the woman's half day school of the woman's Department of the party Ministry of Jiangsu Province, was founded by knob and other women in Jiangsu provincial Party department. As the provisional Executive Committee of the party Ministry of the Jiangsu province has ended, the school is received by the woman's Association of Jiangsu province to be expanded to add professional courses to the women. The promotion of the skills of woman's life is decided to be renamed the present name, in accordance with the purpose of setting up the school, which is not only in charge of the provincial woman's Association, but 
also by private assistance. Niu Minhua, headmaster, asked Wang Xiuduan to be Dean of academic affairs. Modern Chinese woman's vocational schools were also supported by the government.

\section{B. The type of school and the setting of subjects are abundant}

From 1928 to 1936, under the influence of special historical conditions and social environment, modern Chinese women vocational school had distinctive features in the training of students. Mainly in the school type, student learning subjects and student employment.

In the characteristics of school system, modern Chinese women vocational schools formed different types of school system, including full-time vocational schools and short-term vocational schools [4]. The different running mode, directly shows the education of this period China women occupation educational goals, namely, in a relatively short period of time, women training of skilled talents through a variety of ways to improve the overall quality of modern women, improve the status of women as vulnerable groups, and used for the society. In the subject characteristics, occupation education for women in modern times started in the late Qing Dynasty, founded the early occupation school advocates women family education, the family handicraft industry labor skills, the subjects also tend to filature, mulberry, clothing and other subjects, the 1930s China women occupation school subjects had a profound impact set the content and characteristics [5]. At the same time, with the changes of social political climate and the development of industry, the subjects of women vocational schools have also changed a lot since the early years of the Republic of china.

\section{Pay attention to the students' learning conditions and employment}

The investment of modern vocational schools in China mainly focuses on the multiple channels of capital input and the superiority of site selection. The development of Chinese industry from 1928 to 1936 also led to the tilt of educational resources to vocational education. For example, the national vocational education statistics of 1934, published in 1936, was published in 1934. The total number of agricultural, industrial, commercial, domestic and other types of schools totaled three hundred and seventy-two schools, and the number of students was thirty six thousand three hundred and fifty five, and the amount of funds was 6.7 million and five hundred and sixty eight yuan. According to this statistics, there are ten vocational education schools in each province on average, and then their investment is viewed. "Declaration" shows that the national vocational education input in 1934 is 6 million 275 thousand. This number is open to discussion, but in fact, according to incomplete statistics, the percentage of national vocational education funds in secondary education is $24.4 \%$ from 1934 to 1935 .
In the background of the high tide of running a school, the establishment of modern women vocational school has also got a higher social fund contribution. From the "Declaration", the most obvious support is the celebrities, such as the woman's school mentioned in the previous article. The national auspicious woman's vocational middle school was also "deeply sponsored by $\mathrm{Yu}$ Youren, Yang $\mathrm{Hu}$, Xiong Kewu, Yang Shukan and Shanghai famous Huang Jinrong and Fei Gong man". Under the support of the social celebrities, the Chinese woman's work became the regional representative of the practical skills of women in Shanghai.

\section{HISTORICAL INFLUENCE AND ENLIGHTENMENT}

\section{A. The influence of public opinion in ShenBao}

As a new carrier of news dissemination, newspaper public opinion reflects the demand of the masses on the one hand and demonstrates the social hot spot [6]. On the other hand, it plays a great guiding role in the change of readers and people's ideas. In 1872, shortly after its founding, ShenBao wrote: "the purpose of this newspaper is to cover the facts of the current, to describe the truth, the narrative, the political affairs, and the small things of the peasants and businessmen."[7] As a result, the publication of ShenBao was founded on the principle of full coverage. According to its reports, the analysis of the impact of public opinion on modern women vocational schools can be broadly divided into two areas:

First, ShenBao reported that women vocational school is to promote women Liberation. ShenBao emphasizes that women have equal rights to receive education, and that men and women should be equal in social work. Secondly, ShenBao promotes women vocational school through advertisement. ShenBao is often on modern women occupation school enrollment advertising, these ads in the "Declaration" to help obtain economic benefits but also creates conditions for women occupation school social visibility and popularity increased.

\section{B. The historical influence and Enlightenment of modern women Vocational School}

According to ShenBao reported, from 1928 to 1936, the Chinese women vocational school in the community and the support of the government has made certain progress, the modern Chinese women education has far-reaching significance and historical inspiration.

For the individual, the modern Chinese women vocational school has promoted the training of women Vocational skills. The founding of modern women vocational school contributed to the independence and pursuit of freedom and liberation of Chinese women. On the social level, modern Chinese women vocational school promoted the modernization process of Chinese education. Based on the present situation, the historical enlightenment of modern Chinese women vocational school has not been ignored until now:

Vocational education should always be student oriented and attach great importance to the training and employment of students. At the moment, China should explore new types of Vocational schools. For vocational schools, China should increase its investment in schools and change the mode of 
training. Social forces should support vocational schools, and enterprises and individuals should donate vocational education. In the training of students, we should pay attention to the twoway training of family life skills and social labor skills and the all-round development of students.

\section{SUMMARY}

The Modern Woman Chinese Occupation School was created in the background of the awakening of women selfconsciousness and had improved in the movement of women Liberation. It benefited from the social demand and the encourage of all walks of life towards Women Vocational Education. Modern Women Vocational School aims at training women skills to meet the social needs and it had formed a distinctive feature in the school running. Founders of Modern Women Occupation School included the private education, joint education and government schools, that is "a situation of tripartite confrontation" situation. Its investment was relatively high and the types of schools was multiple. Taking into account the development of students' professional skills and their own quality in subjects, this kind of school attached importance to students' employment. At the same time, we should also learn from history and adhere to the "peopleoriented" concept of running schools, and strive to cultivate allround development talents who adapt to the society in order to create a higher level of vocational education.

\section{REFERENCES}

[1] Huangmei. Declaration and woman's education in the late Qing Dynasty, [D]. Soochow University, 2007.

[2] Wang Jianguo, hao ping. Modern woman's career development and woman's Liberation [J]. Journal of Shanxi University (PHILOSOPHY AND SOCIAL SCIENCE EDITION), 2000, (01): 54-57.

[3] Yu Li Fen. [J]. Zhejiang Journal of Western learning and the modern female education, 1996 (03): 122-126.

[4] Dragon and Phoenix. Study of woman's vocational education thoughts in the late Qing Dynasty and the early Republic of China [D]. Hunan Agricultural University, 2007.

[5] Zhang Yuling. On Vocational Education of women in the late Qing Dynasty and the early Republic of China [D]. Jilin University, 2004.

[6] Zhang Lihua. Woman's school education in Jiangsu in the late Qing Dynasty and the early Republic of China [D]. Ningxia University, 2004.

[7] Huangmei. Declaration and woman's education in the late Qing Dynasty, [D]. Soochow University, 2007. 